UCRL-JC-121105

PREPRINT

\title{
Plutonium Gamma-Ray Measurements for Mutual Reciprocal Inspections of Dismantled Nuclear Weapons
}

\author{
Zachary M. Koenig \\ Joseph B. Carlson \\ DeLynn Clark \\ Thomas B. Gosnell
}

This paper was prepared for submittal to the Institute of Nuclear Materials Management 36th Annual Meeting

Palm Desert, CA

July 9-12, 1995

July 1995

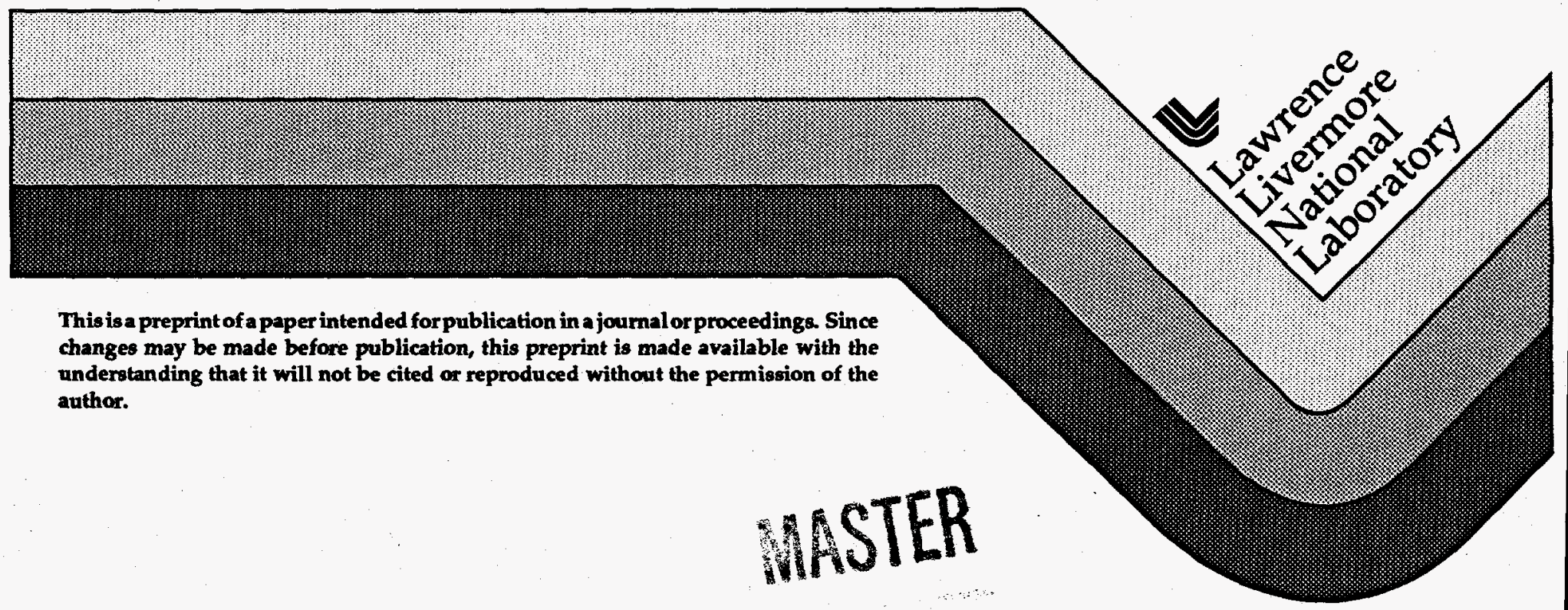

This is a preprint of a paper intended for publication in a journal or proceedings. Since changes may be made before publication, this preprint is made available with the understanding that it will not be cited or reproduced without the permission of the author.

DISTRIBUTION OF THIS DOCUMENT IS UNLIMITED BS 
DISCLAIMER

This document was prepared as an account of work sponsored by an agency of the United States Government. Neither the United States Government nor the University of California nor any of their employees, makes any warranty, express or implied, or assumes any legal liability or responsibility for the accuracy, completeness, or usefulness of any information, apparatus, product, or process disclosed, or represents that its use would not infringe privately owned rights. Reference herein to any specific commercial products, process, or service by trade name, trademark, manufacturer, or otherwise, does not necessarily constitute or imply its endorsement, recommendation, or favoring by the United States Government or the University of California. The views and opinions of authors expressed herein do not necessarily state or reflect those of the United States Government or the University of California, and shall not be used for advertising or product endorsement purposes. 


\section{DISCLAIMER}

Portions of this document may be illegible in electronic image products. Images are produced from the best available original document. 


\title{
PLUTONIUM GAMMA-RAY MEASUREMENTS FOR MUTUAL RECIPROCAL INSPECTIONS OF DISMANTLED NUCLEAR WEAPONS
}

\author{
Zachary M. Koenig \\ Joseph B. Carlson \\ DeLynn Clark \\ Thomas B. Gosnell \\ Lawrence Livermore National Laboratory, Livermore, California, USA
}

\section{ABSTRACT}

The O'Leary-Mikhailov agreement of March 1994 stated that the U. S. and the Russian Federation would engage in mutual reciprocal inspections (MRI) of fissile materials removed from dismantled nuclear weapons. It was decided to begin with the plutonium $(\mathrm{Pu})$ removed from dismantled weapons and held in storage containers. Later discussions between U.S. and Russian technical experts led to the conclusion that, to achieve the O'Leary-Mikhailov objectives, Pu MRI would need to determine that the material in the containers has properties consistent with a nuclear-weapon component. Such a property is a $240 \mathrm{Pu} / 239 \mathrm{Pu}$ ratio consistent with weapons-grade material. One of the candidate inspection techniques under consideration for Pu MRI is to use a narrow region $(630-670 \mathrm{keV})$ of the plutonium gamma-ray spectrum, taken with a high-purity germanium detector, to determine that it is weapons-grade plutonium as well as to estimate the minimum mass necessary to produce the observed gamma-ray intensity. We developed software (the Pu600 code) for instrument control and analysis especially for this purpose. In November 1994, U.S. and Russian scientists met at the Lawrence Livermore National Laboratory for joint experiments to evaluate candidate Pu MRI inspection techniques. In one of these experiments, gamma-ray intensities were measured from three unclassified weapons-grade plutonium source standards and one reactorgrade standard $(21 \% 240 \mathrm{Pu})$. Using our software, we determined the ${ }^{240} \mathrm{Pu} /{ }^{239} \mathrm{Pu}$ ratio of these standards to accuracies within $\pm 10 \%$, which is adequate for Pu MRI. The minimum mass estimates varied, as expected, directly with the exposed surface area of the standards.

\section{INTRODUCTION}

From 14-23 November 1994, U.S. and Russian technical experts met at the Lawrence Livermore National Laboratory in Livermore, California to evaluate equipment and procedures that could support plutonium mutual reciprocal inspections ( $\mathrm{Pu} \mathrm{MRI})$. The experiments were conducted in accordance with discussions between the U.S. and the Russian Federation held in Moscow the month before.

At that October meeting, it was agreed to mutually undertake instrument specification, acquisition, and development that could support MRI measurements. These included: (1) the selection, by both sides, of a commercial, high-purity germanium gamma-ray spectrometer and the development of appropriate software

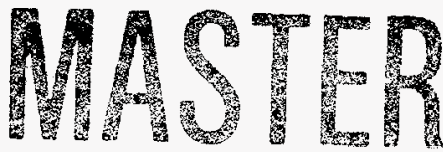


for plutonium isotopic measurements and analysis (actual instrumentation and software to be provided by the U.S.); (2) the provision of the Russian SRPS7 neutron radiation monitor for neutron mass estimates; and (3) the provision of gamma-ray scanning equipment for consideration of plutonium shape measurements (instruments provided by both countries).

This paper specifically addresses item (1), briefly describing the high-purity germanium gamma-ray spectrometer and focusing on the development of software for plutonium isotopic measurements and analysis used in the November joint experiments. The measurement and analysis use data from a narrow band of energy spanning $630-670 \mathrm{keV}$. This relatively high energy region is of secondary value in most safeguards measurements, but is useful in MRI to minimize classification concerns. Because details of the measurement geometry, including incidental absorbers, will generally be unknown, using this high-energy region may be a necessity for some inspections. During these experiments, measurements were made on well-characterized, unclassified plutonium sources, using this spectrometer and software, to demonstrate an instrument, methods, and procedures that could support Pu MRI. No sensitive information was developed or exchanged during this meeting.

\section{INSTRUMENT DESCRIPTION}

The battery-operated gamma-ray spectrometer was assembled from commercial equipment available in our laboratory. It consisted of a portable, N-type, coaxial, high-purity germanium gamma-ray detector of $50 \%$ relative efficiency and a multichannel analyzer with an integral amplifier and bias supply. The analyzer is controlled by a notebook computer running the OS/ 2 operating system. The multichannel analyzer, a Canberra InSpector, provides the necessary battery operation required under expected MRI measurement conditions as well as extensive supporting software that greatly aided automation of measurement procedures. To reduce the intensity of low-energy gamma rays incident on the detector, we placed $1-\mathrm{mm}$ lead and $0.5-\mathrm{mm}$ cadmium absorbers in front of the detector. Batch files were written for automated calibration, background determination, high-voltage control, sample data acquisition, and analysis.

\section{EXPERIMENTAL PROCEDURE}

OS/2 icons on the screen of the laptop computer represent the five batch files used for instrument control and analysis. The batch procedures are initiated with the laptop's pointing device. First, the bias voltage is applied by clicking on its icon. This process establishes a 15-minute warmup to stabilize the spectrometer's electronics. Next, a "state-of-health" batch file is invoked that includes an automated pole-zero and gain check-using a ${ }^{137} \mathrm{Cs}$ check source, which produces a minimum of 100 counts per second in the detector. The third batch file runs a background measurement that acquires data in the 630 - to $670-\mathrm{keV}$ region for the 
same length of time as the inspection measurement. A peak search and analysis are performed on the background data, and any net peak area found is subsequently subtracted from the spectrum of the inspected item. A fourth batch file invokes the inspection measurement and analysis in the $630-$ to $670-\mathrm{keV}$ region. Following data acquisition, the batch process analyzes the spectral data with the Pu600 code to

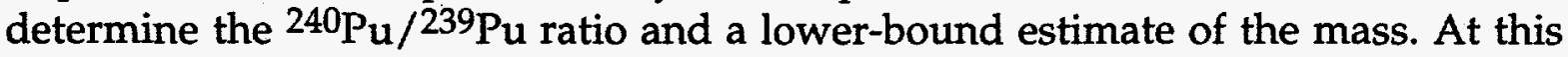
point, more containers can be measured and analyzed and background can be updated if it is believed to be necessary. When all analyses are complete, a fifth batch file shuts down the instrument.

\section{PU600 ANALYSIS CODE}

The Pu600 analysis code was developed specifically for Pu MRI using a methodology adapted from the MGA isotopic analysis code. ${ }^{1} \mathrm{Pu} 600$ was tailored to handle specific issues of an MRI analysis, and numerous validity checks were included to aid automation.

The code analyzes only the 630- to 670-keV energy region of a high-purity germanium detector spectrum. From the analysis, the code calculates the ${ }^{240} \mathrm{Pu} /{ }^{239} \mathrm{Pu}$ isotopic ratio and a lower-bound estimate of total ${ }^{239} \mathrm{Pu}$ in the sample. Pu600 makes numerous validity checks on the spectral data and statistical checks on the analysis process. Failures in the checks result in either warning messages in the output report or, in extreme cases, will cause the code to terminate with a report on the cause of the termination.

Isotopic ratios are derived from a ratio of peaks: the $642.48-\mathrm{keV}$ peak from $240 \mathrm{Pu}$ and the $645.969-\mathrm{keV}$ peak from ${ }^{239} \mathrm{Pu}$. The $658.929-\mathrm{keV}$ peak is used to determine the lower-bound estimate of total ${ }^{239} \mathrm{Pu}$. To compute these peak areas, Pu600 performs a response-function analysis of the entire energy region between 630 and $670 \mathrm{keV}$. Local energy calibration is performed using the $619.00-\mathrm{keV}$ and the $662.42-\mathrm{keV}$ peaks from ${ }^{241} \mathrm{Am}$ as part of the response-function analysis. Absorption corrections are applied to the peak areas for the lead and cadmium absorbers. The code makes no corrections for sample self-absorption or sample container absorption, as these factors will generally be unknown. Ignoring these factors can lead to large underestimates of the $239 \mathrm{Pu}$ mass. However, because attenuation coefficients vary slowly as a function of energy in this region and the peaks chosen are quite close in energy, the correction factor for differential absorption between adjacent peaks is in the range of only a fraction of a percent. Because the Pu600 uncertainty in determining the ${ }^{240} \mathrm{Pu} /{ }^{239} \mathrm{Pu}$ isotopic ratio is typically in the range of $5-10 \%$, ignoring differential sample self-absorption and container absorption has a negligible impact on the calculated ratio.

Before the peaks can be analyzed, the underlying continuum has to be determined and removed. Fixed regions at the extremes of the analysis region are chosen to define the continuum. This approach is used, rather than a more accurate global continuum determination, because of the narrow constraint on the analysis region. These fixed regions are believed to be free of any peaks-although the code 
does check this assumption. The fitting procedure also makes small corrections to the continuum due to the low-energy tails from each of the peaks in the cluster. An empirically derived formula is used to interpolate the continuum region under the peak cluster. ${ }^{1}$

The key peaks in the analysis are clustered within a large number of other peaks from ${ }^{239} \mathrm{Pu}$ and ${ }^{241} \mathrm{Am}$. This is especially true for the $642.48-\mathrm{keV}$ peak from ${ }^{240} \mathrm{Pu}$, which is in close proximity to peaks from both ${ }^{239} \mathrm{Pu}$ and ${ }^{241} \mathrm{Am}$. To correctly calculate the individual peak areas requires a rigorous technique for unfolding the overlapping peaks. A model based on the work of Gunnink ${ }^{2}$ was developed that closely fits a single gamma-ray peak in a high-purity germanium spectrum. The model consists of a Gaussian component with two tailing terms on the low-energy side of the peak, a short- and long-term component. The long-term tail is considered to be part of the continuum.

Using this individual peak model, isotopic peak groups are modeled for each spectral data point as the sum of the contributions from the individual peaks in the group. Pu600 simplifies the isotopic peak group models of the data-reducing the number of free parameters-by exploiting well-known information about the analysis region. The peak areas for all peaks from a given isotope can be related using their emission intensities ${ }^{3}$ and full-energy-peak detector efficiencies. The energy differences between peaks can also be related because they are well known. A fit of the peak group models to the data is accomplished by nonlinear minimization of the weighted residual sum of squares. The isotopic contributions and mass estimate are derived from the fitting coefficients.

Two goodness-of-fit estimates are derived from the fitting process-the value for chi-square from the fit gives an estimate of the overall fit quality. Peak areas are derived by inserting the fitting coefficients for the peak into the Gunnink model and integrating it over the full width of the peak. Estimates of peak area uncertainties are derived through propagation of individual uncertainties in the fitted coefficients through the integration process. The code uses this uncertainty to determine an estimated uncertainty in the isotopic ratio. No uncertainty estimate is made for the ${ }^{239} \mathrm{Pu}$ total mass estimate, as the magnitude of absorption corrections is unknown.

Figure 1 shows the results of a peak fit of a spectrum obtained from an unclassified plutonium standard. The upper plot shows a reconstruction of the fit with dots indicating the measured data. Standardized residuals from the fit are plotted below the reconstruction.

Pu600 makes several validity checks of the spectral data and the results before producing an output report. Gain calibration checks ensure that the code processes the proper region of the spectrum. The linearity and dead-time checks verify that the peak shape has not been distorted by instrumental anomalies.

\section{MEASUREMENT RESULTS FROM THE JOINT EXPERIMENTS}

During the November joint experiments, we measured a number of wellcharacterized plutonium sources. Table 1 lists the certified mass and isotopic ratios for each of these sources. Source geometries included a cylinder $2.86 \mathrm{~cm}$ in diameter 
by $9.88 \mathrm{~cm}$ long, a disk $15.24 \mathrm{~cm}$ in diameter by $1.04 \mathrm{~cm}$ thick, and a sphere $7.00 \mathrm{~cm}$ in diameter. A small amount of material has been removed from the sphere in the form of a truncated conical hole. The PIDI5 reactor-grade source was small enough to be considered a point source.

Table 2 lists the various samples with the associated measurement parameters and the ${ }^{240 \mathrm{Pu} /}{ }^{239} \mathrm{Pu}$ measured ratio and lower-bound estimate of the mass determined by the measurements. Included in Table 2 is the uncertainty estimate associated with the isotopic measurement.

Figure 2 shows the ratio of the measured-to-actual isotopic ratios of $240 \mathrm{Pu} / 239 \mathrm{Pu}$. The error bars are the accumulated errors for both measured and certified values. All of these results are well within one standard deviation of unity, indicating good agreement with the certified values. The uncertainties in the measurements are less than $\pm 10 \%$, quite adequate for the Pu MRI application.

Figure 3 shows the approximately linear function of the lower-bound mass vs the presented area of the plutonium. The presented area is the area of the sample that faces the detector. Because plutonium highly absorbs its own gamma radiation, gamma rays escaping from the sample originate near the plutonium surface. For this reason, the mass estimate for thick samples is seen to vary linearly with the presented area.

Figure 4 shows the ratio of the measured-to-actual mass for the various plutonium samples. Self-absorption of the gamma rays within these thick samples provides a considerable underestimate of the mass-varying from about $20 \%$ when viewing the large surface on the face of the plutonium disk to only about $2 \%$ when viewing the small surface at the end of the rod.

\section{SUMMARY}

The measured isotopic data, when compared with certified values for isotopic standards, indicate that the technique provides sufficient precision and accuracy for application to Pu MRI. We note, however, that since the measured gamma-rays originate only from the surface, there is an assumption that the source has a uniform isotopic ratio throughout. This surface effect also explains why the mass measurements of thick samples produce such low values and are a linear function of the presented surface area.

The following issues were identified by U.S. and Russian scientists that need to be resolved administratively before the suggested method could be incorporated into procedures for Pu MRI. During the measurement, the spectral data are stored both in the computer's internal memory and on a disk. Both sides will want to protect these sensitive data from inadvertent disclosure. The two sides discussed this issue and feel confident that administrative procedures can be developed to protect these data. Currently, during the measurement, the data in the 630- to 670$\mathrm{keV}$ region are displayed on the computer screen so that users can detect any gross anomalies. The software can be easily modified to eliminate this display at the cost of some confidence in data integrity.

At the conclusion of the joint experiments in November 1994, both the U.S. and the Russian Federation agreed that the equipment and procedures demonstrated for 
isotopic measurements and minimum mass estimates provide an adequate technical basis for eventual Pu MRI measurements, provided that remaining administrative issues are resolved. Nevertheless, for classification reasons, none of the proposed Pu MRI methods demonstrated at the joint experiments can be used reciprocally on actual weapon components at this time. This must await the conclusion of an Agreement for Cooperation with the Russian Federation to exchange limited amounts of classified information and a final agreement on measurement methods for implementing Pu MRI.

\section{REFERENCES}

1. R. Gunnink, MGA: A Gamma-Ray Spectrum Analysis Code for Determining Plutonium Isotopic Abundances, Lawrence Livermore National Laboratory, Livermore, CA, UCRL-LR-103220, April 1990, Vol. 1-2.

2. R. Gunnink, W.D. Ruhter, and J.B. Niday, GRPANL: A Suite of Computer Programs for Analyzing Complex Ge and Alpha-Particle Detector Spectra, Lawrence Livermore National Laboratory, Livermore, CA, UCRL-53861, March 1989, Vol. 1-3.

3. R. Gunnink, J.E. Evans, and A.L. Prindle, A Re-Evaluation of the Gamma-Ray Energies and Absolute Branching Intensities of $237 \mathrm{U}, 238-241 \mathrm{P} u$, and ${ }^{241} \mathrm{Am}$, Lawrence Livermore National Laboratory, Livermore, CA, UCRL-52139, October 1976.

Figure Captions

FIGURE 1. PLUTONIUM SPECTRUM WITH 239PU, 240PU, AND ${ }^{241}$ AM CONTRIBUTIONS.

FIGURE 2. MEASURED-TO-ACTUAL ISOTOPIC RATIO OF 240PU/239PU.

FIGURE 3. LOWER-BOUND MASS VS THE PRESENTED AREA OF THE PLUTONIUM STANDARDS.

FIGURE 4. RATIO OF THE MEASURED-TO-ACTUAL MASS FOR THE STANDARDS.

"This work was performed under the auspices of the U.S. Department of Energy by Lawrence Livermore National Laboratory under contract No. W-7405-Eng-48. 
TABLE 1. MASSES AND ISOTOPIC RATIOS OF STANDARD PLUTONIUM SOURCES USED.

$\begin{array}{lcl}\text { Sample } & \text { Mass }(\mathrm{g}) & 240 \mathrm{Pu} /{ }^{239} \mathrm{Pu} \\ & & \\ \text { Rod } & 987 & 0.0627 \\ \text { Sphere } & 2387 & 0.0629 \\ \text { Disc } & 2980 & 0.0620 \\ \text { PIDI5 } & 0.45 & 0.2784\end{array}$

TABLE 2. SUMMARY OF RESULTS OF PU ISOTOPICS AND MINIMUM MASS ESTIMATES.

$\begin{array}{lcccccc}\text { Sample } & \begin{array}{c}\text { Distance } \\ (\mathrm{cm})\end{array} & \begin{array}{c}\mathrm{Pb} \text { shield } \\ (\mathrm{cm})\end{array} & \begin{array}{c}\text { Count } \\ (\mathrm{s})\end{array} & \begin{array}{c}\text { Est. Mass } \\ (\mathrm{g})\end{array} & \begin{array}{c}\text { Isotopics } \\ 240 \mathrm{Pu} / 239 \mathrm{Pu}\end{array} & \begin{array}{l}\text { Isotopics } \\ \text { uncert. (\%) }\end{array} \\ \text { Rod (side) } & 81.5 & 0.1 & 1000 & 118.8 & 0.0615 & 4.9 \\ \text { Rod (end) } & 56.0 & 0.1 & 1000 & 19.9 & 0.0637 & 8.5 \\ \text { Disk (face) } & 170.0 & 0.26 & 1000 & 615.7 & 0.0617 & 5.1 \\ \text { Sphere (side) } & 145.0 & 0.1 & 1000 & 248.6 & 0.0603 & 7.0 \\ \begin{array}{l}\text { PIDI5 21\%- } \\ \text { 240Pu }\end{array} & 7.3 & 0.1 & 1000 & 0.1 & 0.2926 & 7.4\end{array}$




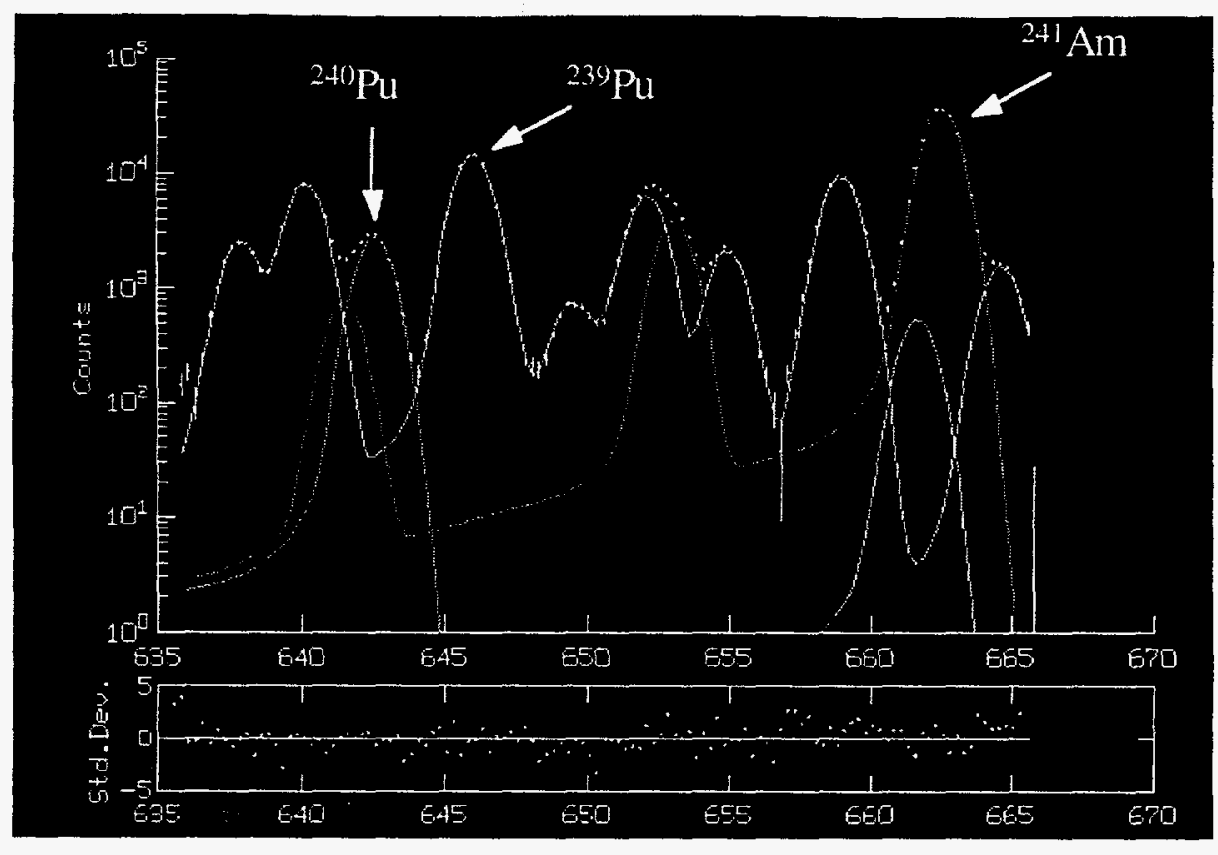

Figure 1 


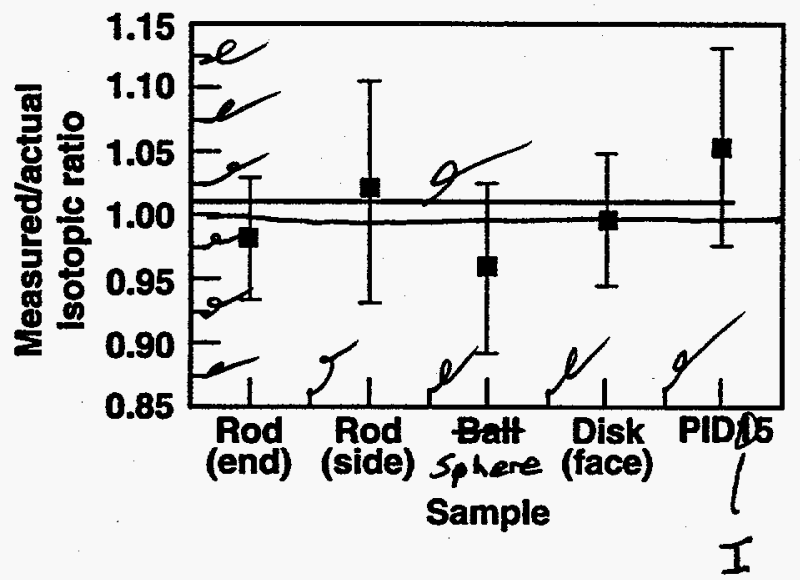

Figure 2 


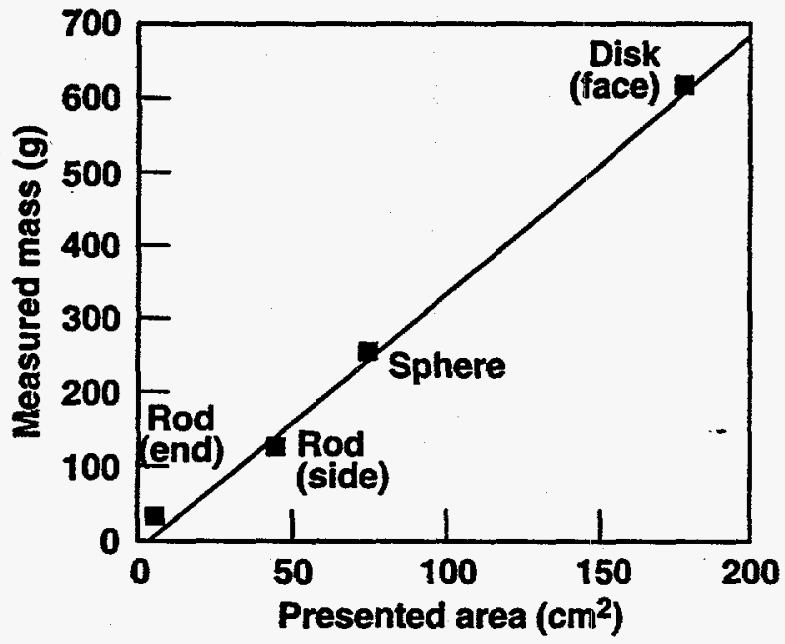

Figure 3 


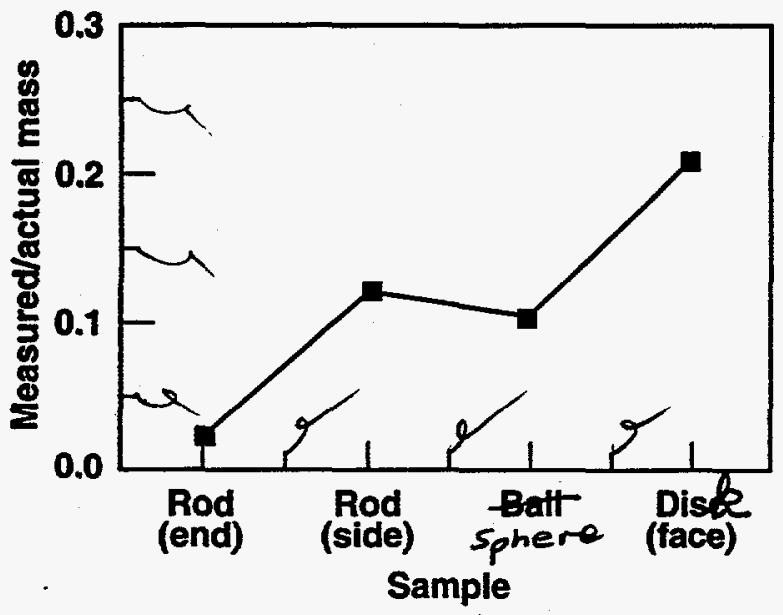

Figure 4 